\title{
Correction to: Association of HIV-infection, antiretroviral treatment and metabolic syndrome with large artery stiffness: a cross-sectional study
}

Titus F. Msoka ${ }^{1 *}$, Gary P. Van Guilder ${ }^{2}$, Yvo M. Smulders ${ }^{3}$, Marceline van Furth ${ }^{3}$, John A. Bartlett ${ }^{4}$ and Michiel A. van Agtmael $^{3}$

\section{Correction to: BMC Infectious Diseases (2018) 18:708 https: $10.1186 / \mathbf{s} 12879-018-3637-0$}

Following publication of the original article [1], the authors reported that they have provided the wrong caption. In Fig. 1 the caption should be "Blood pressure-and sex-adjusted aortic pulse wave velocity (a) and aortic augmentation index (b) in the controls, HIV-1-naive and HIV-1-cART patients with and without metabolic syndrome".

2) The remaining sentence "Aortic pulse wave velocity was $25 \%(P=0.018)$ and $21 \%(P=0.023)$ higher in the HIV-1 cART patients compared with both controls and untreated HIV-1 patients, respectively. There was no significant main effect of metabolic syndrome on augmentation index between the three groups. Values are mean \pm SD. * $P=0.009$ versus HIV-1 cART patients without metabolic syndrome" should be added to at the end of paragraph "Aortic pulse wave velocity in patients with metabolic Syndrome".

(3) The heading "sIndependent predictors of large elastic artery stiffness" should be replaced with "Independent predictors of large elastic artery stiffness".

It has been corrected in the original article as well.

The publisher apologizes for any inconvenience caused by this error.
Received: 15 January 2019 Accepted: 15 January 2019

Published online: 22 February 2019

Reference

1. Msoka, et al. BMC Infect Dis. 2018;18(708) https://doi.org/10.1186/s12879018-3637-0.

\begin{abstract}
Author details
'Department of Internal Medicine, Kilimanjaro Christian Medical Centre, Moshi, Tanzania. ${ }^{2}$ Department of Health and Nutritional Sciences, South Dakota State University, Brookings, SD, USA. ${ }^{3}$ VU University Medical Center, Amsterdam, The Netherlands. ${ }^{4}$ Duke University Medical Center, Durham, North Carolina, USA.
\end{abstract}

\footnotetext{
* Correspondence: ftitus2001@yahoo.co.uk

'Department of Internal Medicine, Kilimanjaro Christian Medical Centre,

Moshi, Tanzania

Full list of author information is available at the end of the article
}

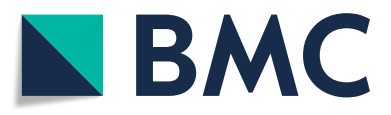

(c) The Author(s). 2019 Open Access This article is distributed under the terms of the Creative Commons Attribution 4.0 International License (http://creativecommons.org/licenses/by/4.0/), which permits unrestricted use, distribution, and reproduction in any medium, provided you give appropriate credit to the original author(s) and the source, provide a link to the Creative Commons license, and indicate if changes were made. The Creative Commons Public Domain Dedication waiver (http://creativecommons.org/publicdomain/zero/1.0/) applies to the data made available in this article, unless otherwise stated. 